\title{
Entre el poder y la autoridad: Mateo Marquín, capitán general de yaquis y mayos de 1843 a 1857
}

\author{
Between Power and Authority: Mateo Marquin, Captain General \\ of Yaquis and Mayos from 1843 to 1857
}

\section{Lucía García Rivera}

EL COLEGIO DE SONORA, lucia_ah@hotmail.com

\section{Zulema Trejo \\ EL COLEGIO DE SONORA, ztrejo@colson.edu.mx}

Las interrelaciones entre los grupos indígenas de Sonora y el Estado han sido un tema recurrente en la historiografía regional de las últimas décadas, abordan mayormente aspectos de enfrentamientos y resistencias. Actualmente la producción historiográfica ha tomado un nuevo auge al profundizar en las relaciones establecidas a través de la negociación y pacificación del territorio indígena. Dentro de esta última perspectiva, este trabajo es una aproximación al estudio del liderazgo indígena en Sonora a través de Mateo Marquín, capitán general del Valle del Yaqui y Mayo. Lo anterior se realiza a través de la propuesta analítica de Martha Bechis y su diferenciación entre el poder y la autoridad. Se utilizan como fuentes los informes oficiales y la correspondencia intercambiada entre los capitanes generales. Partiendo de lo anterior, buscamos aproximarnos al tipo de liderazgo ejercido por Marquín durante 1840 y 1850 en Sonora, así como a la efectividad de su intermediación.

PaLABRAS ClavE: liderazgo indígena, intermediación, negociación, capitán general, yaquis, Mateo Marquín.

The interrelationships of indigenous groups in Sonora and the State have been a recurrent theme in regional historiography in past decades, which focused mainly on aspects of confrontation and resistance. Current historiographical production, however, is experiencing a boom by delving into relationships established through negotiation and the pacification of indigenous territories. Adopting this perspective, the present study presents an approach to the study of indigenous leadership in Sonora through the case of Mateo Marquín, captain general of the Yaqui and Mayo Valley. Our research adopted the analytical proposal of Martha Bechis with its distinction between power and authority, using official reports and records of correspondence among different captain generals as sources. The objective was to understand the type of leadership exercised by Marquín in the 1840s and 1850 s in Sonora and evaluate the effectiveness of its processes of intermediation.

KEYWORDS: indigenous leadership, intermediation, negotiation, captain general, Yaquis, Mateo Marquín

Fecha de recepción: 16 de diciembre de 2015 / Fecha de aceptación: 19 de agosto de 2016 / Fecha de version definitiva: 31 de octubre de 2016 


\section{INTRODUCCIÓN}

1 estudio de los grupos indígenas es un tema que recientemente tomó nuevo auge en la historiografía sonorense. En un balance rápido de los temas y grupos investigados salta a la vista que los yaquis son los más estudiados, le siguen los mayos de cuyo devenir histórico se han investigado momentos concretos como su participación en la revolución de 1910 y la época misional; esta última temática está circunscrita al espacio ocupado por los mayos en el actual estado de Sinaloa. ${ }^{1}$ Los seris y ópatas también se han investigado con regularidad, aunque en el caso de los primeros su estudio ha correspondido más a disciplinas como el derecho, la sociología, lingüística y antropología que a la historia, ${ }^{2}$ la excepción la constituyen los trabajos de José Luis Mirafuentes. ${ }^{3}$ En cuanto a los ópatas, grupo ya extinto, es Cynthia Radding quien mayormente los ha investigado. ${ }^{4}$

A fin de ensanchar la veta abierta por las recientes investigaciones acerca de los grupos indígenas en Sonora, en las páginas siguientes presentamos una primera aproximación al estudio del liderazgo

${ }^{1}$ La conexión Yocupicio: soberanía estatal y tradición cívico-liberal en Sonora 19131939 de Ignacio Almada es uno de los pocos trabajos en los que se trata de manera más o menos profunda algunos aspectos de la participación de los mayos en la etapa de la revolución de 1910. El poblamiento en tierra de indios Cahitas de Gilberto López Castillo es ejemplo de las investigaciones que en época reciente se han ocupado de estudiar a los mayos en la época colonial.

${ }^{2}$ Algunos trabajos realizados desde estas disciplinas son "Costumbres normativas de los seris” de César Córdova Casas; “'Sé que estoy enfermo, ¿y qué hacer?’ La diabetes mellitus y sus significados entre los comcaac de Socaaix (Punta Chueca), Sonora” de Pedro Yáñez.

${ }^{3}$ Domingo Elizondo, Noticia de la expedición militar contra los rebeldes seris y pimas del Cerro Prieto, Sonora, 1767-1771, ed., introd., notas y apéndices de José Luis Mirafuentes y Pilar Máynez (México: Universidad Nacional Autónoma de México, Instituto de Investigaciones Históricas, 1999); José Luis Mirafuentes G., "Colonial Expansion and Indian Resistance in Sonora: The Seri Uprisings in 1748 and 1750", en Violence, Resistance, and Survival in the Americas. Native Americans and the Legacy of Conquest, ed. William B. Taylor, 101-123 (Washington: Smithsonian Institution, 1994).

${ }^{4}$ Los pimas, altos y bajos, han sido objeto de estudio de forma más bien indirecta puesto que a los pimas altos se les estudia en el contexto de las misiones fundadas por el jesuita Eusebio Kino, y a los pimas bajos suele agrupárseles con los ópatas dado la porosidad de los límites tangibles y simbólicos entre uno y otro grupo. 
indígena en Sonora, mediante el análisis del liderazgo de Mateo Marquín, capitán general del Yaqui durante las décadas de 1840 y 1850. En este artículo cuestionamos si Mateo Marquín fue un líder por autoridad o poder durante el periodo que fungió como capitán general de yaquis, especialmente, en los ańos de 1846 durante la sublevación de Miguel Esteban, y de 1854 cuando se produjo el intento de despojo de los terrenos de Babójori y Aguacaliente. Para lo anterior, utilizamos como fuente informes del Valle del Yaqui y Mayo, redactados por autoridades indígenas y mestizas que relatan la situación imperante en la región del Yaqui; asimismo usamos la correspondencia intercambiada entre Luis Tánori, capitán de ópatas, y Mateo Marquín, capitán del Yaqui.

Como marco teórico utilizamos las propuestas de Martha Bechis (2008) quien explica la naturaleza de los cacicatos y jefaturas en el área Arauco-pampeana en el siglo XIX, ${ }^{5}$ con base en los textos de Morton Fried (1967) para diferenciar la autoridad del poder, así como de Marshall Sahlins (1979) para conocer las cualidades de mando del "gran hombre melanesio". La aplicación de los conceptos básicos de la autora sirvieron de base para una diversidad de estudios posteriores que abordan los liderazgos políticos en contextos fronterizos, se refieren principalmente a la naturaleza del poder y su estructura segmental. A partir de lo anterior retomamos a Néspolo para conocer la concepción que tienen los indígenas de la autoridad y el poder, así como las formas de obtenerlo y controlarlo. Asimismo, los textos de Ingrid de Jong (2009) para explicar la posición inherente al estatus y la autoridad como efecto de su comunidad.

${ }^{5}$ Durante la década de los ochenta en Argentina, Martha Bechis abrió el estudio de las interacciones pacíficas entre ambas sociedades a partir de las relaciones fronterizas dando margen a estudios que se retoman en este trabajo tales como los de Ingrid de Jong (2009) y Eugenia Néspolo (2009); donde plantea el desplazamiento del centro de interés de los conflictos armados hacia las formas pacíficas de interacción que adoptaron los grupos indígenas en Argentina y Chile durante la transformación de los estado-nación. En este sentido, destacó la actuación de los liderazgos políticos para las negociaciones con la sociedad no indígena; definió la estructura segmental que alude a la configuración política formada por la división de unidades autosuficientes más pequeńas que la sociedad, sin la existencia de una estructura política superior que las contenga (De Jong 2007, 16); así como una tipología de liderazgo indígena con la finalidad de diferenciar entre la autoridad y el poder por el cargo. 
Los trabajos de antropología política de Swartz, Turner y Tuden (1966) permiten conocer el apoyo que otorgan sus seguidores al líder, a través de la legitimidad y conductas futuras.

\section{TERRITORIO Y ESTRUCTURA DE GOBIERNO YAQUIS}

Los yaquis habitan en el valle que lleva su nombre situado en Sonora entre la Sierra Madre Occidental y el Golfo de California, entre los paralelos $27^{\circ} 10^{\prime}$ y $27^{\circ} 50^{\prime}$ latitud norte, y los meridianos $109^{\circ} 55^{\prime}$ y $110^{\circ} 36$. En términos históricos la delimitación del valle del Yaqui fluctuó de acuerdo a las circunstancias políticas, favorables o adversas, a la sociedad indígena que lo habita. La referencia histórica más antigua con la que contamos respecto a la delimitación del territorio yaqui se encuentra en la crónica del jesuita Andrés Pérez de Ribas, quien señaló que, en la primera mitad del XvII, los yaquis habitaban el territorio que ocupaba las doce últimas leguas que recorría el río Yaqui, antes de desembocar en el mar. De acuerdo al misionero el Yaqui se componía de "muchos valles, alamedas y tierras de sementeras, las quales quando el rio trae sus avenidas y crecientes, que son ordinarias casi cada año, las dexa mojadas y humedecidas para poderse sembrar de verano" (Pérez de Ribas 1647, 284).

A parte de la descripción del territorio yaqui citada en el párrafo anterior consideramos importante destacar una cuestión a la que Pérez de Ribas alude varias veces: la fertilidad de las tierras del valle, cuestión que será constantemente utilizada como motivo para justificar la necesidad de establecer colonos en el Yaqui, con el fin de sacar el mayor provecho posible a esas feraces tierras que a ojos de la sociedad no indígena permanecían ociosas. La riqueza de los terrenos del Yaqui las describió Pérez de Ribas con las siguientes palabras:

antes de que entren las aguas, que suelen començar a principios de julio, ya ha alçado sus semillas los Indios, y esta es su principal cosecha: no obstante que por tiempos de aguas suelen algunos bolver a sembrar aunque de esta cosecha poco caso se haze, porque su principal sustentento les dá la del verano que de ordinario es abundante de frixol, calabaça, y otras semillas que ellos usan (Pérez de Ribas 1645, 284). 
Las descripciones del misionero jesuita, así como las evidencias de prosperidad de las misiones del Yaqui a lo largo de los siglos transcurridos antes de su secularización, sentaron las bases para que el territorio que ocupaban se constituyera en manzana de la discordia entre los yaquis y la sociedad no indígena, ya que los segundos aspiraban a tomar posesión del fértil territorio yaqui, en tanto que los primeros se negaban a permitir la entrada de blancos y mestizos. Vale la pena aclarar que cuando mencionamos la negativa de los yaquis a admitir a personas ajenas a la etnia en sus tierras, no soslayamos el hecho de que sí hubo establecimiento de blancos y mestizos en territorio yaqui, sin embargo, consideramos que su presencia fue mínima, por consiguiente, prácticamente intrascendente por lo menos en las primeras siete décadas del siglo XIX. ${ }^{6}$

A la llegada de los jesuitas, en territorio yaqui habitaban caciques indígenas quienes fueron los primeros en pactar para sentar las bases de la misión (Pérez de Ribas 1645, 238), que se concretaron en el establecimiento de una estructura de gobierno que contemplaba los ámbitos civil y religioso, en los cuales, si bien los indígenas tuvieron una participación activa, eran los misioneros quienes ocupaban el estrato más alto de la jerarquía misional siguiéndole el cacique con el puesto de gobernador del pueblo de misión. Esta forma de organización perduró hasta la secularización de las misiones en la segunda mitad del siglo XviII.

$\mathrm{Al}$ secularizarse las misiones del Yaqui éstas no se convirtieron en repúblicas de indios oficialmente; cómo se gobernaron los yaquis en el lapso que transcurrió entre la salida de los jesuitas y el advenimiento del proceso de independencia es un tema que no se ha estudiado a profundidad, aunque de manera general se sabe que de una u otra manera la estructura de gobierno establecida por los misioneros siguió funcionando. ${ }^{7}$

${ }^{6}$ Los informes que a lo largo del siglo xIx se enviaban a las autoridades respecto a los sucesos en el valle del Yaqui muestran que había presencia de vecinos (blancos o mestizos) en algunos pueblos yaquis como Torim; esta información por lo general era escueta y daba cuenta de las personas que morían al inicio o durante el transcurso de una rebelión de los yaquis.

${ }^{7}$ La tesis "Representación política de antiguo régimen y la transición al liberalismo en una zona de frontera, Sonora 1650-1824” de José Marcos Medina es el estudio más 


\section{LOS CAPITANES GENERALES}

Si bien, anteriormente, se mencionó el pacto realizado entre misioneros y caciques indígenas para sentar las bases de la misión resaltando la posibilidad de que existieran personajes dentro del grupo que tuvieran autoridad y legitimidad dentro del territorio yaqui antes de la llegada de los jesuitas, el cargo de Capitán general data de los tiempos de la monarquía hispana. Algunos autores sostienen que el puesto fue creado por los jesuitas como parte de la estructura de gobierno de las misiones del septentrión novohispano. A partir de los trabajos clásicos de Sergio Ortega ${ }^{8}$ se da por hecho, con algunos matices, que el gobierno indígena de la misión estaba encabezado por "el gobernador, cuya función consistía en mantener el orden dentro de la comunidad, juzgar las disputas que había en el pueblo y castigar a los culpables" (Ortega y del Río 2010, 68). Si bien, Ortega describió al detalle los cargos civiles y religiosos que ocupaban los indios de la misión, a los militares apenas les dedicó unas líneas: "en algunas comunidades había también un capitán, nombrado por el capitán español, cuya función era organizar el servicio militar para auxilio de las fuerzas españolas" (Ortega y del Río 2010, 68).

Esta escueta afirmación acerca de la organización política y militar de los indios fue la única información que se tuvo por mucho tiempo respecto al tema. A partir del nuevo milenio, los trabajos de María del Valle Borrero y José Marcos Medina contribuyeron a matizar la afirmación hecha por Ortega Noriega en 1993. ${ }^{9}$ Medina explicó que el cargo de capitán general fue traído por los colonizadores al asentarse en territorio mexicano, donde la Corona premiaba a los "adelantados" o caudillos de las huestes con tierras, exenciones o privilegios, tal como lo hicieron con las huestes espańolas en la expulsión de los árabes (Medina 2011,29). La práctica anterior tuvo una

reciente que existe con respecto al gobierno de los pueblos indígenas de Sonora en el periodo de transición entre la secularización de las misiones y el México independiente.

${ }^{8}$ Historia General de Sonora tomo II, Trescientos años de historia sonorense y Un ensayo de Historia Regional. El Noroeste de México 1530-1880.

${ }^{9}$ Año en que se publicó por primera vez el libro Trescientos años de historia sonorense. 
particularidad en el septentrión novohispano: los indígenas formaban parte de las huestes (Medina 2011, 29 y 30).

En las instituciones fronterizas como misiones y presidios, el cargo de capitán general se constituyó en una figura de autoridad importante para los indígenas, ya que en esa época estaba estipulado que se nombrara un capitán general para cada etnia, este puesto permaneció fuera de la jurisdicción del misionero, pues, su nombramiento provenía directamente del rey (Medina 2011, 35). Lo anterior ocasionó que muchas veces quienes ocuparon el cargo tuvieran mayor autoridad de la ejercida por gobernadores o alcaldes, ya que éstos estaban estrechamente vinculados a las decisiones políticas de los misioneros (Medina 2011, 36).

\section{EL CARGO DE CAPITÁN GENERAL ENTRE LOS YAQUIS}

Entre los yaquis el origen del cargo de capitán general se encuentra ligado a las necesidades fluctuantes de la guerra sostenida por la Corona española en las provincia de Ostimuri; de ahí que a diferencia de los ópatas que llegaron a convertirse en auxiliares de las compañías presidiales, debido a que habitaban la zona desde donde se expandía la frontera de colonización, los yaquis mantuvieron una participación intermitente en la estructura militar colonial, y sólo participaban en ella cuando los capitanes españoles solicitaban indios al misionero para sus campañas (Ramírez Zavala 2014, 24).

El carácter temporal de las milicias yaquis se fue perdiendo de tal forma que se convirtieron en una estructura permanente al interior de las misiones; de esta forma el jefe de las milicias adquirió el rango de capitán general que tenía como función "los de proteger y mantener el orden en las misiones; bajo su mando estaba un cuerpo de defensa compuesto de indios de su nación estructurado como las milicias occidentales. Entre sus responsabilidades debía escoger a los indios que apoyarían en la contención de los gentiles y rebeldes, además de seleccionar a los sujetos que saldrían a trabajar a las minas" (Ramírez Zavala 2014, 25).

Los capitanes generales se elegían en una asamblea pública al interior de la misión, aunque los candidatos eran previamente selec- 
cionados por el misionero y el gobernador. El capitán de la gobernación de Sonora y Sinaloa extendía el nombramiento oficial a quien resultara seleccionado. Ramírez Zavala señala que el cargo de capitán general era vitalicio, aunque ello no fue obstáculo para que las autoridades españolas destituyeran a quienes consideraban que no cumplían con las funciones que estaban a su cargo.

En el periodo postindependiente, el cargo de capitán general continuó vigente para las sociedades indígenas de Sonora, su existencia se regularizó a través de la Ley particular para el gobierno de los pueblos indígenas promulgada el 30 de septiembre de 1828, meses después de finalizada la primera fase del levantamiento de Juan Banderas. En lo que respecta a los capitanes generales esta ley ratificó el nombramiento de quienes ya se ostentaban como tales, y acotó la vigencia del cargo hasta la muerte de quienes lo ejercían en ese momento. En sucesivas leyes expedidas para regular la vida política de los indígenas de Sonora, el cargo de capitán general se suprimió o restableció de acuerdo a las circunstancias del momento. ${ }^{10}$

Durante el periodo que abarca este trabajo el capitán general era una pieza fundamental para la interacción entre las autoridades estatales y los yaquis. El capitán general del Yaqui no vinculaba a su persona a los ocho pueblos yaquis (Spicer 1994, 223); la unión de toda la sociedad yaqui en torno a su figura se producía sólo en momentos de confrontaciones con otras sociedades indígenas como los mayos, o con las autoridades estatales. En tiempos de paz el capitán general tenía poder efectivo sólo sobre sus seguidores, que la más de las veces incluían tanto a los que formaban parte de su milicia como a civiles indígenas que habitaban en los ocho pueblos.

El intento de radicar todo el poder en la persona del capitán general influyó para que se incrementara el faccionalismo al interior de las etnias; ${ }^{11}$ en términos analíticos hemos clasificado estas divisio-

\footnotetext{
${ }^{10}$ Para mayor información respecto a las leyes especiales para el gobierno indígena se puede consultar el artículo de Zulema Trejo, "Leyes especiales para el gobierno de los pueblos indígenas. Sonora, 1831-1853".

${ }^{11}$ Como se mencionó anteriormente, las fricciones entre las autoridades civiles como alcaldes y gobernadores, y el capitán general tuvieron su origen en la época misional ya que los primeros dependían en gran medida de los misioneros, en tanto que el segundo estaba fuera de su jurisdicción; con el tiempo estas diferencias propiciaron la
} 
nes al interior de los yaquis como parcialidades, la cuales definimos como los grupos que estuvieron encabezadas por líderes que se mantenían como tales debido al cargo, mientras que otros lo hacían merced la autoridad y sus relaciones con el poder estatal. Las categorías de liderazgos basados en el cargo y la autoridad las retomamos de la historiografía argentina y serán descritas con mayor amplitud en los siguientes párrafos.

El liderazgo por autoridad, o por el cargo, alude a criterios que sirven para distinguir las diversas formas del poder político y los medios por los cuales quienes lo detentan obtienen los efectos deseados (obtenerlo y controlarlo). En cuanto a las formas, existen dos categorías de análisis: autoridad y poder (Néspolo 2009, 84). La autoridad se relaciona con la concepción que tienen los indígenas sobre su organización política, y se distingue por la habilidad que tiene su promotor de canalizar la conducta de otros en ausencia de amenazas (De Jong 2009, 16); el poder por la posición es una cualidad inherente al estatus que ostenta el líder mientras el otro es un efecto del reconocimiento de su comunidad, independientemente de que ostente un cargo o no.

En nuestro trabajo los líderes indígenas son aquellos que ejercen el poder político mediante la autoridad, que está afianzada por atributos como el dominio de la oratoria, la negociación y capacidad de mando para atraer seguidores; asimismo legitiman su poder ante las autoridades estatales detentando un cargo político que los posiciona en el lugar adecuado para fungir como intermediarios entre la etnia y las autoridades no indígenas.

\section{El liderazgo de Mateo Marquín}

Mateo Marquín fue capitán general del Yaqui y Mayo por al menos veinte ańos; estas dos décadas de ejercicio del poder lo llevaron a adaptarse a las circunstancias cambiantes de su entorno político, tales como cambios de sistema de gobierno y el establecimiento de

formación de facciones al interior de las sociedades indígenas, que se incrementaron cuando los capitanes generales intentaron concentrar en su persona tanto el poder militar como el civil. 
diferentes grupos de notables en el ejercicio del poder estatal, sin que ello mellara su liderazgo entre los yaquis. La permanencia de Marquín como capitán general de yaquis y mayos a partir de 1853, estaba sustentada por las leyes especiales para el gobierno de los pueblos indígenas, básicamente las emitidas en 1828 y $1847^{12}$ (Trejo 2013,114 ) en las cuales se establecía que el cargo de capitán general tenía carácter vitalicio, que se extinguía al morir las personas que lo ocupaban al momento de promulgarse la ley, esas personas eran en ese momento el yaqui Mateo Marquín y el ópata Luis Tánori.

Siguiendo los postulados de Martha Bechis, en Marquín se apreciaban más las características de los líderes por autoridad que por el cargo: su forma de mediación era la negociación entre la sociedad yaqui y la sonorense. Marquín dominó la oratoria y tuvo poder de convocatoria; sin embargo es innegable que su reconocimiento como capitán general tanto por parte de las autoridades estatales como de los yaquis y mayos fue pieza clave para mantenerse en el cargo por tanto tiempo. El liderazgo por autoridad de Marquín fue percibido por la sociedad yaqui como un canal de mediación entre ellos y las autoridades estatales; en tanto que el estado lo concebían como un líder militar que podía asegurar la paz en los valles del Yaqui y Mayo, que geográficamente constituían la parte sur de Sonora.

MEDIAR Y PACIFICAR EN UN PERIODO CONFLICTIVO: I 843 -I 854

Como antecedente del periodo mencionado anteriomente, en 1837, Anastasio Bustamante eligió como primer gobernador cen-

${ }^{12}$ Dichas leyes provenían de legislaciones realizadas por el Estado Interno de Occidente que comprendía los estados de Sonora y Sinaloa. Después de su escisión en 1830, algunas legislaciones para los grupos indígenas quedaron vigentes, siendo la "Ley especial para el gobierno de los pueblos indígenas" una de ellas y mantuvo su vigencia de 1828 a 1847. En 1847, el gobierno de Sonora la derogó y promulgó la "Ley para los pueblos indígenas de Sonora" que tuvo una duración de seis años (Trejo 2013, 113). Finalmente, en mayo de 1853 se publica oficialmente la "Ley para el gobierno de los pueblos yaquis" en donde en el artículo 11 n.242 establece que "No habrá capitanes ni tenientes generales en los pueblos indígenas, a ecepción de Mateo Marquín y Luis Tánori, cuyos títulos ha confirmado el Gobierno General, pero sin mas facultades que cumplir las órdenes del Gobierno que las autoridades de su resorte les comuniquen". 
tralista de Sonora a Manuel María Gándara de una terna compuesta por éste, Simón Elías Gonzáles y José Urrea; la inconformidad de Urrea por la designación se manifestó en 1838, cuando se pronunció por el federalismo y depuso a Gándara de la gubernatura. El derrocamiento de Manuel Gándara por parte de Urrea desencadenó un suceso conocido en la historiografía sonorense como el conflicto Gándara-Urrea, que perduró de 1837 a 1846. De tal forma, los años de 1843 a 1845 se caracterizaron por cambios políticos constantes en la gubernatura del estado.

Mientras José Urrea ocupó el cargo de gobernador denunciaba continuamente al grupo gandarista encabezado por Pedro Romo y Juan Muńoz, quienes, afirmaba, se presentaban como representantes de "los gobernadores de los ocho pueblos capintancillos y oficiales”. Pedro Romo, también fue mencionado por Urrea como dependiente de las haciendas gandaristas y por tal motivo los acusó de apoyar a las fuerzas del desorden y mover a los pueblos del río, quienes bajo el pretexto de combatir a los apaches están constantemente armándose y preparándose para una "nueva revolución”. En las circulares que existen entre este último y los capitanes generales Luis Tánori, Mateo Marquín y Pedro Romo mencionado como autoridad del yaqui, establecen estar esperando noticias del nuevo cambio de gobernador y comandante general a favor de Manuel Gándara o Teofilo Romero:

No tarda en reunir tanto por esto como por que D. Ancelmo Larrondo y otros deben de estar en el mayo con seiscientas ballonetas porque sin moverse de mi hasta que no llegue el Sor. Gobernador Comandante general unos dicen que es Sor. Manuel María Gandara y otros que el General Teofilo Romero y que con el bienen los señores gandaras en fin ya debes saberlo pues ha llegado el extraordinario a ures nos bamos a estar en estos pueblos hasta no ver las ordenes del gobierno= no dejen de noticiarme lo que ocurra por esos mundos ${ }^{13}$

${ }^{13}$ Archivo General de la Nación (AGN) / México Independiente / Gobernación y relaciones exteriores / gobernación / caja 0576 (269 sin sección) / exp. 6 / doc. 42 
¿Qué posición mantiene Mateo Marquín ante los sucesos anteriores? Si bien, dicho capitán general demuestra su subordinación a las órdenes de quien ejerza el cargo de gobernador-en este caso el general Urrea $-{ }^{14}$ también hay un interés especial en mantener sus relaciones con las autoridades indígenas de Luis Tánori y Pedro Romo. De tal forma, en los años de 1845 y 1846, Marquín ejerce su poder a través de la mediación política; estableciendo enlaces entre las autoridades estatales y las indígenas, aconsejando, a esta última, sobre las acciones que se tomarán en el río para pacificar la zona. Entre ellas se encuentra hacer visitas a los poblados para identificar familiares de rebeldes o cabecillas, recibir a Manuel María Gándara como comandante militar del río y alertar a las autoridades indígenas de los cambios políticos a nivel nacional que posiblemente lleven "seductores" a la zona.

Lo anterior refleja el poder ejercido durante esta década por Mateo Marquín. ¿Qué entendemos entonces por liderazgo? Según Talcott Parsons (1963) el liderazgo se refiere a la obtención de la obediencia mediante la influencia; en él se llevan a cabo decisiones ganando el apoyo del grupo a través de la convicción de que éstas están acordes a sus intereses. En este sentido, el líder ejerce una influencia en ausencia de amenazas, a través de una apelación independiente y "activación de compromisos" sobre la base de que determinada forma de comportarse es una "cosa buena" (Swartz, Turner y Tuden 1966, 113).

En el ejemplo citado anteriormente, Marquín explica que la actuación del gobierno estatal representado por el comandante militar Manuel María Gándara debe de ser bien recibida por los pueblos del río, ya que lleva como objetivo común -entre los blancos e indios- restablecer la paz y la tranquilidad en el río, de tal forma, deben de aceptar la incursión de Gándara y sus colaboradores a esta

${ }^{14}$ Marquín dirige una circular a Urrea explicando que lo han informado mal acerca de los sublevados del Yaqui. Menciona que "tambien es falso que reunieron todas las autoridades [del Yaqui], todo es nulo eso... lo que si decimos que amamos a nuestra familia, a nuestro rio y a todo genero humano y sobre todo a la tranquilidad es la que preferimos los pueblos". AGN / México Independiente / Gobernación y relaciones exteriores / gobernación / caja 0576 / exp. 6. 
zona. Mientras que ustedes, menciona Marquín "deben descanzar [sic] en la confianza de cualquiera que sea el sistema que nos rija, portándose V.V. como hasta aquí, esta superioridad les asegura que siempre deben contar con los aucilios y protección a que le hacen acreedores con ser obedientes y fieles al gobierno". ${ }^{15}$ Con esto se confirma la activación de compromisos: si los pueblos yaquis y sus autoridades ayudaban a establecer la paz y perseguían a los cabecillas sublevados haciendo correrías en las haciendas aledañas, debían tener por seguro que el Estado los proveería de auxilios, protección así como posibles gratificaciones: "Tomando en concideracion los servicios que v. ha prestado y los de sus ayudantes Evaristo y Martin, va a dictar ese gobierno sus ordenes a fin de que se le pague a V. Mensualmente un sueldo de veinte y nueve pesos y a los citados Evaristo y Martin el de diez y ocho cada uno, también mensuales". ${ }^{16}$

La circular anterior se centra en un suceso fundamental de 1846, cuando Marquín derrota las fuerzas comandadas por el indígena mayo Miguel Esteban, ${ }^{17}$ quien se "abrograba el título de capitán general de aquel río (Mayo)". ${ }^{18}$ Así, pues, Miguel Esteban sofocó la rebelión del mayo a quien se le unieron un grupo de yaquis provenientes de los pueblos de Bacum, Cocorit y Vicam, posiblemente con el objetivo de contrarrestar el liderazgo de Mateo Marquín sobre todos los pueblos yaquis. A partir de lo anterior, ejejerce un liderazgo por autoridad si existen pueblos de su misma etnia contrarios a su poder?

Para comprender la oposición de dichos pueblos yaquis, que se representa en la sublevación de Miguel Esteban hacia el liderazgo de Mateo Marquín, es conveniente trasladarnos a principios de la década de 1840 cuando Juan María Jusacamea ocupaba el cargo de capitán general del Yaqui. La contraposición de éste y su homóni-

${ }^{15}$ AGES / F Ejecutivo / caja 45 / tomo 160 / Ures, noviembre 23 de 1846.

${ }^{16}$ AGES / F. Ejecutivo / oficialía mayor / caja 45 / tomo 160 / Ures, noviembre de 1846.

${ }^{17}$ Miguel Esteban era un indio mayo que se rebeló entre los ańos de 1845-1846, consiguió unir en su rebelión a yaquis y mayos. El gobierno estatal envió al Manuel María Gándara a sofocar esta rebelión, lo que hizo con la ayuda de Mateo Marquín.

${ }^{18}$ AGES / F. Ejecutivo / caja 45 / tomo 160 / Guaymas, marzo 23 de 1846. 
mo, Juan Ignacio Jusacamea o Juan "La Bandera", ha sido estudiada por Cuauhtémoc Hernandéz Silva (1997) y mayormente por Raquel Padilla Ramos (2010). A Juan Banderas se le identificó por ser el promotor de una insurrección que traía consigo enmiendas de índole étnica: apelaba a la integridad territorial, a la expulsión de los espańoles y subrepticiamente al derecho a la autodeterminación. Su liderazgo se forjó claramente como uno de autoridad: a sus seguidores imponía respeto a razón de su gran poder de convocatoria, lo cual hacía referencia más que a jefes militares, a líderes morales. Sin embargo, es Juan María Jusacamea quien forja la alianza para empoderarse como capitán general, posterior a la aprehensión y fusilamiento de Juan Banderas.

La estrategia que utilizó Juan María Jusacamea, para ser favorecido por las autoridades estatales, fue en un principio de adaptación y sometimiento (Hernández 1997, 196). Evelyn Hu Dehart explica que Jusacamea trató de implementar las propuestas del gobernador Manuel Escalante que se remitía a separar en parcelas privadas el territorio yaqui según las leyes de 1828 (Hu Dehart 1984, 51). A partir de lo anterior, un grupo de yaquis de los pueblos belicosos trataron de remover a Jusacamea del poder, a lo cual el gobernador Manuel Escalante opuso resistencia, ya que no quería perder a un fiel sirviente del poder estatal en momentos de difícil coexistencia (Hu Dehart 1984, 51).

Jusacamea muere en el año de 1842 (Hu Dehart 1984, 51) a manos de una "banda de rebeldes" que provenían del interior del valle del Yaqui. Después del apoyo recibido por el poder estatal, Jusacamea se preocupó por legitimar y lograr la permanencia de su cargo conjuntando a un buen número de seguidores que se desligaron del movimiento de Banderas. Asimismo, subiendo al cargo de capitán general "no favoreció la instauración del nuevo orden liberal” (Hernández 1997, 196), se rebeló contra las mismas autoridades que ańos antes habían otorgado su apoyo. A pesar de las diferencias acerca de la figura de Juan María Jusacamea, los autores concuerdan en que este último estuvo relacionado con el poder estatal, que ejerció gracias a su fidelidad y a contrarrestar fuerzas rebeldes de Banderas. 
Posiblemente, la imagen del personaje anterior fue la más cercana del cargo ejercido por un capitán general, que le fue transmitida a Mateo Marquín. En este sentido, en un principio, su actividad política estuvo relacionada con lo ejecutado años atrás que se distinguía por la alianza con las autoridades estatales, así como el respeto a los estatutos impuestos por éstas. Tras el asesinato de Juan María Jusacamea en 1842 a manos de "una banda de rebeldes", Mateo Marquín asumió el cargo de capitán general del río Yaqui y Mayo, realizando una ardua labor para encontrar a los cabecillas rebeldes que habían dado muerte a Jusacamea. En una de sus circulares dirigidas a las autoridades indígenas del río Yaqui establece:

Para consolidarla [la paz] espera el gobierno de la actividad y eficacia de V. que persiga contudentemente a los cabecillas de la rebelión, y a los que han cometido los atroces asesinatos de Juan Maria Jusacamea, de Sacarias Armenta, y de D. Manuel Aguilar a fin de reducirlos a prisión y aplicarles el castigo que las leyes les señala por tan horrendo crímenes es preciso que el malo pague sus delitos para que los buenos vean que al gobierno castigándolos procura concervarles la paz y tranquilidad de sus pueblos y de su familia, a si mismo que les asegura sus intereses. ${ }^{19}$

La circular anterior se enmarca dentro de la sublevación de Miguel Esteban en 1846, sin embargo, en ella se hacía referencia al asesinato que años antes, en 1842, habían ejecutado los pueblos rebeldes de Bácum, Cócorit y Vícam en contra de Juan María Jusacamea; de tal forma menciona que ellos fueron los ejecutores del asesinato de Jusacamea y recientemente de la muerte de Manuel Francisco Aguilar, ministro de guerra y comisionado de la persecución de los sublevados del Yaqui. Marquín debía poner especial atención en estos pueblos para pacificar la zona del valle, ser beneficiado por las autoridades estatales al encontrar al asesino de un ministro allegado al poder estatal, y consolidar su poder ante los grupos yaquis que claramente marcaban su oposición a su liderazgo.

${ }^{19}$ AGEs / F. Ejecutivo /Oficialía mayor / caja 45 / tomo 160 / año 1846 / Ures noviembre 23 de 1846. 
La autopercepción de Marquín como líder militar encargado de mantener la paz del Mayo y Yaqui se evidencia también en el fragmento de una carta enviada al teniente general del Mayo Ignacio María Cruz: "Hoy he determinado salir al Pueblo de Cocori con mi fuerza con el fin de perseguir a toda clase de perversos, como U. sabe no es otro mi objeto, ${ }^{20}$ mas como he tenido parte del mismo Gobierno que Miguel Esteban se ha fugado de donde lo tenían acompañandolo porcion de perversos y cabecillas antiguos de este rio". ${ }^{21}$ Es evidente en esta cita que Marquín reconoce cuál es el objetivo de su cargo, el hecho de hacérselo explícito a su destinatario es una forma de énfasis que busca, como se ve líneas más adelante, justificar las acciones que va a ejecutar; esas líneas posteriores muestran a un líder no sólo con iniciativa propia que informa de sus acciones, antes de solicitar autorización para realizarla; sino también hace evidente que Marquín sabía que las autoridades estatales confiaban en él para la pacificación de indígenas rebeldes, no en vano fue él quien sofocó la rebelión de Miguel Esteban.

A partir de un diálogo establecido entre Marquín, Manuel María Gándara y Miguel Esteban, éste fue confinado a una hacienda de Gándara en donde él y su familia recibieron amnistía por la sublevación que protagonizaron. Con lo anterior se puede constatar la importancia de la intermediación de Marquín para pacificar a los rebeldes y a su cabecilla principal, negociando con él una estancia tranquila como "castigo" a su movimiento; este favoritismo hacia la persona de Miguel Esteban refleja la negociación efectiva llevada a cabo por Mateo Marquín, que si bien conocía la oposición de ciertos grupos yaquis hacia su liderazgo, los que se habían unido a la sublevación de Esteban, prefirió pactar pacíficamente con el líder del movimiento y contrarrestar su oposición. De tal forma, si bien el capitán general era un líder por autoridad aceptada por la sociedad blanca y la indígena, éste no aglutinaba los intereses políticos del común de la etnia, sin embargo, buscaba consolidar su poder a tra-

${ }^{20}$ Cursivas nuestras.

${ }^{21}$ Carta de Mateo Marquín a Ignacio María Cruz, 24 de septiembre de 1847 en AGEs / F. Ejecutivo / ramo Prefecturas / t. 180 / año 1847. 
vés de distintas acciones: ejecutar la pacificación el valle, apelar a las autoridades indígenas y negociar con los grupos sublevados.

Si bien, el liderazgo y su relación con las autoridades estatales en pos de pacificar los valles al ejercer el cargo fue relativamente sólido durante dichos años, Padilla y Trejo (2012) mencionan que a partir de 1854 la lealtad de Marquín comenzó a "flaquear" (Padilla y Trejo 2012 , 76). Trejo y Revilla profundizan lo anterior analizando una averiguación de 1854 con relación a una reunión que se estaba llevando a cabo en Tórim, y de la cual no tenían conocimiento las autoridades estatales. Los autores no mencionan quién se encontraba en el gobierno en ese momento, ya que para 1854 fueron tres gobernadores quienes se alternaron el cargo: Manuel María Gándara, José María Yañez y Domingo Ramírez de Arellano. Posiblemente este documento se elaboró durante un gobierno diferente al de Manuel María Gándara, y con la finalidad de menguar el poder individual y central de Marquín desde su misma etnia, ya que la averiguación se ejecutó a través del alcalde mayor del Yaqui, Policarpio Murillo (Trejo 2012, 9).

Para comprender mejor lo anterior se debe señalar que en el año de 1854 en Sonora, el ámbito político se caracterizaba por cambios en el gobierno estatal: en plena revolución de Ayutla, el 16 de octubre de 1854, fue electo el general Domingo Ramírez de Arellano para el puesto de gobernador y comandante militar del departamento. Dicho acto se ejecutó para sustituir al general José María Yañez (Ruibal 1997, 142-143), quien fue llamado a la Ciudad de México. Poco tiempo después, Domínguez de Arellano renunció al cargo, dejando al general Pedro Espejo en el poder, quien mantuvo una alianza cercana a Pesqueira y José de Aguilar, opuestos al poderío de Gándara (Acuña 1981, 35-39). El contexto político anterior es relevante mencionarlo, ya que es justamente cuando Pesqueira y su grupo toman el poder político en Sonora se inician las dificultades para los líderes indígenas que ostentaban el cargo de capitán general.

Realizando una recapitulación de los planteamientos anteriores, para la década de 1840, durante el periodo en el cargo de Mateo Marquín, si bien hay acciones subversivas de yaquis, las partidas de rebeldes fueron menos frecuentes y las existentes fueron mediadas por 
dicho personaje. Sin embargo, en la década de 1850, especialmente en los años de 1854 y 1855, es cuando la autoridad del capitán general y el reconocimiento por las autoridades estatales comienzan a mermar. Las razones se refieren a la muerte del capitán general Luis Tánori, que al seguir una partida de apaches fue atacado en la sierra el Rancho de los Yaquis, ${ }^{22}$ así como la muerte de Marquín en la defensa de San José de Guaymas al lado de Gándara contra las fuerzas pesqueiristas. Con la muerte de ambos personajes se extingue el cargo de capitán general, lo que será utilizado por las fuerzas pesqueiristas para menguar el poder político de los grupos indígenas en Sonora.

\section{LÍDER POR AUTORIDAD EN EL YAQUi, REBELdE ANTE EL PODER ESTATAL}

En este apartado nos dedicamos a analizar los acontecimientos que rompieron la estabilidad pactada entre Mateo Marquín y Manuel María Gándara a finales de la década de 1850. Si bien se analizará el descontento yaqui acerca de la posesión de terrenos del Babójori y Aguacaliente por Manuel y Fernando Ińigo, tomaremos algunos sucesos anteriores, durante y posteriores, a dicho conflicto que consideramos importantes para argumentar a favor de nuestra propuesta de considerar el liderazgo de Martín, durante este periodo, como un liderato por autoridad. Cabe resaltar que políticamente suceden situaciones al interior del grupo yaqui de forma simultánea a oposiciones políticas dentro de las elites de notables que buscaban su predominio en el Estado; que confluyeron con las sublevaciones indígenas de este periodo.

Es importante destacar que en un periodo de estabilidad relativa entre autoridades mestizas e indígenas, se dio margen para realizar legislaciones que garantizaran el orden y tranquilidad de la zona tales como las expedidas en 1853 por Manuel María Gándara, donde se delimitaba la estructura del gobierno civil y militar que debía existir en el Yaqui. La creación de nuevos cargos como la subprefectura y jueces de paz de la zona del Yaqui así como la permanencia de

${ }^{22}$ AGES / F. Ejecutivo / R. Prefecturas / t. 283 / Álamos, mayo 23 de 1854. 
los tradicionales como alcaldes, gobernadores y capitanes generales, buscaban según Zulema Trejo (2012) ser una "pieza legislativa de transición encaminada a convertir los ocho pueblos tradicionales en ayuntamientos" (Trejo 2012, 117) lo cual proveía la posibilidad de integrar finalmente a los grupos indígenas a la sociedad blanca que se estaba conformando en ese momento (Trejo 2012, 117).

Sin embargo, al interior de los yaquis, los efectos de esas legislaciones fueron otros: la diferencia entre cargos por posición, al interior de la etnia como los alcaldes y gobernadores, se contrapuso a líderes por autoridad como Mateo Marquín. Si bien, este último también detentaba un cargo político, fue la convergencia entre su cargo y su autoridad lo que produjo que su poder se extendiera durante al menos dos décadas en el estado. En este sentido, si bien las legislaciones de 1853 buscaban delimitar la estructura civil y militar de los yaquis, lo que se percibe en la documentación es una constante falta de acuerdos entre autoridades indígenas acerca de qué cargo detentaba mayor poder y relevancia; asimismo, la figura del subprefecto del río Yaqui produjo un nuevo intermediario no indígena que mediaba entre las autoridades estatales y las étnicas, apelando constantemente en contra del poder de acción que el capitán general del Yaqui tenía. ¿Fue éste el propósito original de las legislaciones? ¿Minar a las autoridades étnicas y fragmentar su poder? Para resolver lo anterior, analizaremos el conflicto entre autoridades yaquis durante la posesión de terrenos del Babójori y Aguacaliente. ${ }^{23}$

\section{LOS FAVORES PERDIDOS: EL BABÓJORI y AgUaCALIENTE}

A principios de marzo de 1854, durante el gobierno del general José María Yańez, se acrecentó el descontento de un sector de los yaquis a razón del despojo a los indios de los terrenos del Babójori y Agua-

${ }^{23}$ Este caso alteró la tranquilidad en los pueblos del río Yaqui derivado de las disputas entre la familia Ińigo y los indígenas ubicados en el valle de Agua Caliente y Babójori. Dichas tierras, fueron reclamadas por Ińigo para establecer plantaciones para el cultivo de algodón en dicho territorio argumentando que tal medida daría un impulso económico a la entidad. Dichos territorios a decir de Hernández Silva, pertenecieron a los yaquis desde tiempos coloniales, y se encontraban entre los más prósperos de todo el Yaqui (Hernández Silva 1996, 103). 
caliente por Manuel y Fernando Ińigo. El prefecto del Distrito de Guaymas, Francisco Irigoyen, pidió aumentar su escolta de hombres, a razón del movimiento que reinaba en el valle. ${ }^{24}$ Así, pues, recomendó que se detuvieran las providencias de amparo ejecutadas por Iñigo para no causar malestar entre los indígenas. ${ }^{25}$ Para el $25 \mathrm{de}$ febrero de 1854, el subprefecto del Yaqui, Francisco Gómez Mayer, reportó que Mateo Marquín fue el que "[a] causado el malestar de los indios, al alucinar a otros cabecillas como lo son Loreto Ibarra gobernador del Cocorit, José Mayor gobernador de Bacum y Juan Nabojoa del Cocorit". ${ }^{26}$

Tanto Irigoyen como Gómez Mayer solicitaban constantemente se les dotara de hombres y de parque, ya que no podían contener una sublevación de yaquis si ésta tenía lugar, a raíz del favor con el que habla de Ińigo y a la falta de respuesta de las autoridades estatales ante la demanda de cartuchos, éstos no se enfrentaron frontalmente a los yaquis $y$, en cambio, comunicaron a la autoridades estatales el posicionamiento de los indígenas; ante lo anterior Irigoyen reporta:

Hoy se me ha presentando el Alcalde mayor del rio Yaqui [Juan José Armenta] y otro indigena que vienen comisionados por los ocho pueblos del mencionado rio, representando contra el agravio dicen se les ha inferido en el asunto de los terrenos del Babájori. En apoyo a su derecho me han manifestado que Don Manuel Iñigo no estableció como había ofrecido la maquinaria de mantas en los susodichos terrenos y que tampoco dio cumplimiento a la promesa de abrir una toma de agua que regando el Babájori aprovecharía también á las tierras de los indígenas que por estas ofertas no reclamaron no hicieron tampoco posteriomente por que Yñigo ha mantenido abandonadas las tierras en cuestión y el uso común de estas ha estado al arbitrio de los indígenas sin ninguna intencion. ${ }^{27}$

Para lo anterior menciona Irigoyen que era necesario establecer un nuevo subprefecto del yaqui, "VS debe cuidar de la defensa de los

\footnotetext{
${ }^{24}$ AGES / F. Ejecutivo / t. 18 / exp.8 / febrero 16 de 1854.

${ }^{25}$ AGES / F. Ejecutivo / t. 18 / exp.8 / febrero 20 de 1854.

${ }^{26}$ AGES / F. Ejecutivo / t. 18 / exp. 8 / febrero 25 de 1854.

${ }^{27}$ AGES / F. Ejecutivo / t. 18 / exp. 8 / 11 de marzo de 1854 .
} 
derechos de los indígenas; no permitiendo que despoje de la posecion”28. ¿Quién era este nuevo defensor de indios? ¿Por qué el nombramiento de un nuevo subprefecto? La documentación no nos permite constatar que sucedió con Gómez Mayer y por qué se buscaba que alguien ocupara su cargo; posiblemente, este personaje no era depositario de la confianza e intereses de los indios, lo cual conllevaba a una sublevación definitiva. ¿Era Mateo Marquín el personaje idóneo para establecer las negociaciones del Bábajori y Aguacaliente? ¿Era posible un intermediario de confianza para las autoridades estatales y los indígenas? Lo anterior provocó la pugna entre dos autoridades del Yaqui por la "carrera" de defensor de propiedad de los indios del Babójori y Aguacaliente, lo cual es mencionado por Mateo Marquín, quien escribe al gobernador José María Yañez:

el 19 de este mes que rige, salio [Juan José Armenta] de guíviris para el pueblo de Bican, en donde hiso junta a los poblanos y les dijo vieran pues y se desengańaran que todos los pedidos que manifiesto al gobernador vuelbe nada por que V.E no me atiende ami por que no tengo facultades para nada y que solo el esta facultado para todo, y de alli se paso al pueblo de --- donde hiso lo mismo que en Bicam y Torim. ${ }^{29}$

En lo anterior podemos distinguir la disputa entre dos autoridades: el alcalde mayor del Río, Juan José Armenta, y el capitán general, Mateo Marquín, quienes buscaban ejercer su autoridad entre sus seguidores buscando su apoyo y deslegitimando al otro. No estaban claros para los indígenas los lineamientos acerca de qué autoridad ostentaba mayor poder dentro del río, cuestión que para antes de 1853, al menos en la documentación sí está que el capitán general era el encargado de establecer las acciones en el río con el propósito del control, pacificación, así como la mediación política que velaba por sus intereses. En este sentido, en el mismo documento Mateo Marquín apela a "la esperanza de que todo esto lo arreglara

${ }^{28}$ Ibid.

${ }^{29}$ AGES / F. Ejecutivo / t. 18 / exp. 8 / Ramo indígenas mayos-ópatas / Guaymas 2 de agosto de 1854 . 
$\mathrm{V}$. con la justa conducta de mis servicios que he dado hace mas de 20 años al puro gobierno de este departamento de Sonora" dejando en claro que o "se me afirma mi pedido de toda inteligencia y quitarme de padecer o me quita a mi de la carrera y nombra un comisionado para que este pase a los Rios y saque estos hombres que no me dejan trabajar y solo aci se arreglaran estos dos Rios" ${ }^{\prime 30}$.

Se percibe en la carta de Marquín el disgusto que siente al ver amenazada su autoridad ante los yaquis, al mencionar que no era posible que "un hombre impedido me perjudique tanto de todas maneras". ${ }^{31}$ Asimismo, si bien pide el favor que se le otorgue "toda inteligencia" también dice abiertamente que lo saque de la carrera de defensor de indios o nombre un comisionado; en lo anterior, es notorio que más que postularse por un nuevo cargo, su preocupación más inmediata es el descrédito ante sus seguidores propiciado por Juan José Armenta. ¿Por qué el posible "desinterés" por ser nombrado comisionado? Las legislaciones especiales de 1853 determinaban, en uno de sus postulados, que no se volverían a nombrar capitanes ni tenientes generales una vez que murieran los que poseían ese puesto. De tal forma, posiblemente, Mateo Marquín tenía asegurado su cargo, al menos hasta su muerte, sin embargo, este tenía que ser sólido y duradero manteniendo su autoridad dentro del río Yaqui y ante las autoridades estatales.

En la documentación posterior a este suceso, un nuevo subprefecto del río aparece como firmante: José Pérez. Este continuamente se queja con Irigoyen de las acciones independientes que tomaba Mateo Marquín al no darle cuenta de sus correrías. Solicitaba se le ratificara si éste "es subalterno suyo se lo haga entender [A Marquín] que se sabe que anda diciendo quel Babajori se lo van a dar al gobierno y anda moviendo a su gente". ${ }^{32} \mathrm{~A}$ lo anterior Mateo Marquín contestó que "no me considero subalterno suyo para darle cuenta como me dice, tengo mi jefe inmediato, ya este le daré parte de mis correrías" asimismo cita a las legislaciones especiales $1853^{33}$ que

\footnotetext{
${ }^{30}$ Ibid.

${ }^{31}$ Ibid.

${ }^{32}$ AGES / F. Ejecutivo / t.18 / exp.8 / doc. 013519 / Huíviris agosto 30 de 1854.

${ }^{33} \mathrm{El}$ artículo 11 de las legislaciones especiales de 1853 al que hacen referencia ambos
} 
hace José Pérez, donde se estipula que Mateo Marquín es su subalterno, dice "que V. me cita el artículo 11 de ley del estado n.242 fecha 7 de mayo de 1853, creo que al hacerlo la leido muy ligeramente, y no atendió a su sentido literal, pues si lo ignora recurra preguntar a los que mas saben". ${ }^{34}$

Para este momento, se distingue que el liderazgo que ejerció Mateo Marquín por al menos una década cambió de sentido: las bases de su liderazgo por el cargo comenzaron a menguar a razón de la elección de un nuevo gobernador, y nuevas legislaciones que si bien reconocen su cargo, también dan margen de interpretación sobre las órdenes que éste debe seguir; asimismo, las autoridades estatales que antes garantizaban su actuar y dominio sobre su demarcación, ahora cuestionan sus acciones y la independencia de éstas. Así pues, Marquín utilizó su legitimidad dentro del río juntando seguidores en pos de la defensa del Babójori "que a nombre de Mateo se asomasen a defenderse de los enemigos que vienen, que las mismas autoridades del Rio estan comprometidas a entregar las tierras" 35 incitándolos a tomar las armas en contra de las mismas autoridades del Rio; ${ }^{36}$ en este sentido, recurría a sus seguidores a través de actos benefactores como es la repartición de semovientes entre los pobladores del grupo que lo apoyaba. ${ }^{37}$

Resulta relevante la ubicación de los pueblos que otorgan su apoyo a Marquín en que corresponden a Vícam, Tórim, Bacúm y Cócorit al extremo norte del Yaqui, donde se ubican los terrenos del valle de Aguacaliente y Babójori; el valle de Aguacaliente se localiza a un lado de la sierra del Bacatete que corresponden a unos terrenos importantes para la región. El grupo opuesto políticamente a Mar-

personajes cita lo siguiente: "No habrá capitanes ni tenientes generales en los pueblos indígenas, a ecepción de Mateo Marquín y Luis Tánori, cuyos títulos ha confirmado el Gobierno General, pero sin mas facultades que cumplir las órdenes del Gobierno que las autoridades de su resorte les comuniquen”.

${ }^{34}$ AGEs / F. Ejecutivo / t. 18 / exp. 8 / Ramo indígenas mayos-ópatas / doc. 013523 / Huíviris agosto 30 de 1855.

${ }^{35}$ AGES / F. Ejecutivo /t. 18 / exp. 8 / Ramo indígenas mayos-ópatas / doc. 013529 / Huíviris septiembre 9 de 1855.

${ }^{36} \mathrm{Ibid}$.

${ }^{37}$ AGES / F. Ejecutivo / t. 18 / exp. 8 / Ramo indígenas mayos-ópatas / 30 agosto 1855 
quín se ubicaba al otro extremo del río y era representado por el subprefecto José Pérez, Juan José Armenta, Mariano Matus, Pedro Balenzuela, Ignacio Botori y Lorenzo Guapo. ${ }^{38}$

Para el año de 1855 existió una continua demanda por parte de las autoridades del río Yaqui, en especial de José Pérez quien demandaba al Prefecto Francisco Irigoyen intercediera ante los continuos desacatos de sus órdenes por parte de Mateo Marquín. La denuncia hacía referencia a la actitud altanera de éste y a las "tropelías" hacia su persona, asimismo justificaba el hecho de que fue "arraigado en el puerto de Guaymas" por conducto de José María Yañez a razón de su conducta en Pótam. En dicho pueblo, regaló borregos en todo el río a sus pobladores, afectando los intereses del general Yañez. ${ }^{39}$ Tomando en cuenta lo descrito anteriormente como parte del liderazgo por autoridad de Mateo Marquín, es posible considerar a sus seguidores como subalternos, ${ }^{40}$ quienes reciben bienes materiales por seguir a un líder que contaba con los recursos necesarios para otorgarlos.

En el mismo sentido, el alcalde mayor del río Yaqui, Armenta, denuncia también la conducta sospechosa de Mateo Marquín; mencionaba como fue visto en Babójori y Aguacaliente en la compañía de 600 indios. Armenta explicó que Marquín les dijo a quienes lo seguían, que destituyeran a Armenta de su cargo ya que no peleaba por los derechos de los indígenas sobre los terrenos del Babójori. Dicha denuncia fue consultada con Marquín, quien responde que la correría la realizó porque se le notificó que en el terreno señalado se estaba sembrando tabaco, y con la finalidad de detener dichas cosechas, decidió dirigirse a la zona en compañía de un grupo de indígenas; menciona cómo fue calumniado por Armenta y los

${ }^{38}$ Manuel María Gándara envía a Mateo Marquín una orden para sacar del río por "las buenas o a balazos" a semejantes personajes. La circular menciona que esos sujetos son los que están realizando desmanes en el río y que si ellos salen de ahí, todo se aplacará. AGES / F.Ejecutivo / t. 18 / exp. 8 / septiembre de 1855.

${ }^{39}$ AGES / F.E. / t. 18 / exp. 8 / Ramo indígenas mayos-ópatas / 7 de mayo de 1854.

${ }^{40}$ El subalterno es una persona que se encuentra en relación de alteridad con otro -en este caso el líder indígena- en condición inferior. Ambos guardan una oposición de intereses que los unifica y dota de conciencia de su actuar político al interior de la parcialidad. Según Ortner (1995), lo anterior puede suceder cuando el frente de oposición tiene su propia política interna que se establecen jerarquías dentro del grupo subordinado. 
habitantes de esta zona, pide se explique al gobernador sus verdaderas intenciones al dirigirse a los terrenos del Babójori.

Recapitulando lo anterior, a principios de 1854 y con el restablecimiento de Manuel María Gándara en la gubernatura, se apeló a él para suspender la posesión por parte de Manuel y Fernando Ińigo de los terrenos del Babójori. Asimismo se dio una orden para elegir un "defensor de indios" que interviniera en un tribunal y sólo vencidos en éste, se podría despojarlos de dichos territorios. La disputa de Juan José Armenta y Mateo Marquín por ser el defensor de indios solicitado por el poder estatal, desencadenó de nueva cuenta la división entre los pueblos yaquis apoyando a uno u otro personaje. Claramente, Mateo Marquín veía su dominio político peligrar por la salida de Gándara del poder, eso amenazaba la independencia de sus acciones en el río tanto por el subprefecto como por los jueces de paz. A raíz de esta amenaza reunió a un grupo grande de seguidores con la enmienda de defender sus intereses a razón del descontento de la toma del Babójori y Aguacaliente, por parte de las autoridades estatales, fue una opción para fortalecer su liderazgo por autoridad y por poder.

En el panorama anterior se percibe evidentemente una negociación entre Marquín y Gándara para no intervenir en los terrenos del Babójori y Aguacaliente, cercanos a la frontera de San José de Guaymas (Spicer 1994, 180). Posteriormente la negociación se vio interrumpida con la inestabilidad política en la gubernatura del estado, en donde se sucedieron en los años de 1854 a 1856 cinco gobernadores alternados a Manuel María Gándara (cuadro 1).

Cuadro i. Gobernantes de Sonora durante el periodo de 1854-1856

Manuel María Gándara

José María Yáñez

Manuel María Gándara

Domingo Ramírez de Arellano

Pedro Espejo

Manuel María Gándara

José de Aguilar
Junio de 1853-abril de 1854

Abril-septiembre de 1854

Septiembre-octubre de 1854

Octubre de 1854-junio de 1855

Junio-septiembre de 1855

Septiembre de 1855-marzo de 1856

Marzo de 1856-agosto de 1856

Fuente: Trejo 2012. 
En misivas posteriores de Mateo Marquín se habla de un "acto sagrado" en el que tienen que congregarse por el bien general de la nación, con lo que probablemente se refiriera al nuevo ascenso de Gándara a la gubernatura, durante el periodo septiembre de 1855-marzo de 1856 (Trejo 2004, 48), su último periodo en la gubernatura de Sonora. Así, pues, en este mismo año con la actividad nacional que se gestaba entre conservadores y liberales, así como el ascenso del liberalismo de Benito Juárez, Ignacio Pesqueira lucharía "bajo la égida del nuevo gobierno de reforma" (Spicer 1994, 180), viéndose reflejado en Sonora a raíz de la rivalidad entre GándaraPesqueira.

Mateo Marquín fue una pieza fundamental en el combate a las fuerzas pesqueiristas en las luchas realizadas en la zona de San José de Guaymas. Durante los dos primeros ańos de lucha, las fuerzas de Gándara aunadas a los yaquis lograron mantener la frontera del territorio Yaqui en San José de Guaymas. Posiblemente, la negociación que existió entre ambos personajes (y las demandas por el territorio del valle de Aguacaliente) se refería a mantener la frontera interna entre los pueblos del extremo este como Torim, Bacum y Cocorit. Cuando Gándara perdió su cargo, y se produjo la muerte de Mateo Marquín en un tiroteo en agosto de 1856, la frontera interna, que se había negociado hasta ese momento, se perdió.

Para ejemplificar lo anterior, durante el gobierno de Gándara y su grupo se detuvo el acceso de nuevos colonos a las áreas que se conocían tradicionalmente como territorio Yaqui, argumentando inclusive a favor de los indígenas cuando era necesario. Para 1857, con las fuerzas comandadas por Pesqueira, aunada a la muerte de Mateo Marquín, los territorios del Babójori y Aguacaliente finalmente fueron invadidos por Jesús García Morales directamente desde Tórim, puerto yaqui del Médano y Cócorit. Así pues, se estableció un cuartel general del ejército en el valle y la zona que una vez fue pactada por los yaquis a través de Marquín: el valle de Aguacaliente (Spicer 1994, 180).

¿Cómo fue entendido el cargo de capitán general por Ignacio Pesqueira? El poder estatal, representado por Pesqueira, buscaba el efecto contrario a los gobiernos anteriores: suplantar el cargo de ca- 
pitán general, que provenía de tiempos coloniales y cuyos mecanismos no eran compatibles con el nuevo orden liberal. Asimismo, fragmentar el poder de los grupos indígenas creando rivalidad al interior de la etnia entre cabecillas opuestos al liderazgo de Marquín. El propósito principal del nuevo gobierno fue colonizar territorios prolíficos para el estado en pos de su progreso, que no eran compatibles, como los ideales políticos, con los capitanes generales, quienes habían ejercido por décadas su intermediación política.

El liderazgo por posición pactado entre autoridades estatales y Mateo Marquín se ve menguado con la salida y entrada de Gándara en el poder. Al cargo de capitán general, se le añadirán jefes inmediatos como el subprefecto del río y, ante el poder estatal, los gobernadores y alcaldes tendrán más relevancia para el estado. En este sentido, las actividades que realizaba Mateo Marquín iban a ser supervisadas por José Pérez subprefecto no indígena del río Yaqui y Mayo. Ante esta situación, Marquín es relacionado con los cabecillas rebeldes ante las disposiciones estatales; acusándolo de mover cabecillas en su favor y contrariar las órdenes seguidas por los jueces de paz de Huiviris.

A partir de lo expuesto anteriormente, es posible ver con mayor énfasis la legitimidad y el liderazgo por autoridad que ejerció Marquín ¿Qué esperaban los indios de los pueblos del interior del Yaqui? Para dichos pueblos, dedicados tradicionalmente a las labores agrícolas, era importante la cuestión del territorio y la amenaza de colonizar el Babójori y Aguacaliente sin ejecutar lo pactado por Ińigo conllevaba serios riesgos ¿veían los indios en Marquín un líder que podría pactar con Gándara a su favor? Posiblemente, esa fue la "conducta futura" ( Swartz, Turner y Tuden 1966, 106) que los grupos del interior del Yaqui buscaron como seguidores del liderazgo de Marquín. La conducta futura entonces son las expectativas en función de que la entidad que se legitima satisfaga ciertas obligaciones que deben de cumplir quienes ven esto como legítimo; pueden ser específicas, como un jefe legítimo que hará que llueva cuando sea necesario; en este sentido, ellas operan como predicciones de lo que ocurrirá en el futuro (Swartz, Turner y Tuden 1966, 106 y 107). 
Por otra parte, unirse a los rebeldes del interior del Yaqui ¿Qué implicaba para el liderazgo de Marquín? A través del apoyo a Gándara, Marquín buscaba se le retribuyera al cargo la importancia que anteriomente detentaba. Como él mismo solicitaba, quería se quitaran jefes inmediatos como el Subprefecto del valle del Yaqui a quien él no reconocía y, por lo tanto, no debía dar cuenta de sus correrías. Asimismo, destacaba que su objetivo seguía siendo pacificar la zona y que estas personas sólo dificultaban su trabajo "quedando intensamente apacionado y con la esperanza de que todo esto lo arreglara sobre la justa conducta de mis servicios que he dado hace mas de veinte años al puro gobierno de este departamento de Sonora”. ${ }^{41}$

\section{Consideraciones finales}

En la historiografía sonorense, el estudio de los liderazgos indígenas como tales es una cuestión apenas tocada, por lo tanto, el tema desarrollado en este artículo se inscribe en la vertiente abierta hace aproximadamente una década, relativa a la participación activa de los grupos indígenas en el escenario político sonorense. El ángulo que elegimos para desarrollar nuestra investigación fue el estudiar el caso del capitán general yaqui Mateo Marquín. A través de su trayectoria expusimos los elementos que caracterizaron su liderazgo al frente de yaquis y mayos, la percepción que las autoridades estatales y seguidores de este líder que unió en su persona tanto las características de los líderes por autoridad, como por el cargo, aunque en el caso concreto de Marquín prevalecieron las primeras sobre las segundas.

En una tierra de frontera y disputa por el dominio territorial entre dos sociedades, la indígena y la mestiza, así como la pugna entre los grupos de notables por hacerse con el control del gobierno, el papel de las sociedades indígenas fue determinante; yaquis, ópatas y mayos poseían una estructura militar que podía inclinar la balanza hacia uno u otro de los bandos en disputa, de ahí que para la época se viera en los líderes indígenas una carta de triunfo si conseguían tenerlos como aliados. Para ello no dudaron en mantener vigentes

${ }^{41}$ AGES/ F. Ejecutivo/Tomo 18/ exp. 9/ Guaymas 2 de agosto de 1854. 
cargos que databan de la época de la monarquía hispana, como el de capitán general, siempre y cuando quien ocupara el puesto estuviera dispuesto a mantener la paz en el territorio bajo su jurisdicción, aunque esto propiciara la creación de divisiones al interior de una etnia.

El reconocimiento de Mateo Marquín como pacificador e intermediario no se puso en tela de juicio en tanto no se opusiera a las autoridades estatales aliadas. Durante el gobierno intermitente de Gándara a partir de la segunda mitad de la década de 1840, los pactos existentes entre Mateo Marquín y el poder estatal se remitían principalmente a establecer la paz en las zonas del río Yaqui y Mayo y controlar su tranquilidad. Mateo Marquín fungió como un mediador político que con apego a la ley era un enlace informante entre autoridades estatales e indígenas, no siempre teniendo la aceptación de la mayor parte de su etnia. Sin embargo, cuando las sublevaciones se suscitaron en dicho periodo, estableció negociaciones efectivas con los rebeldes al orden estatal pactando con sus cabecillas, como el caso de Miguel Esteban.

Los primeros años de Mateo Marquín en su cargo, refieren a un liderazgo por posición en donde se remite a ejecutar acciones militares por encargo de las autoridades estatales; sin embargo, su liderazgo se fue restructurando hasta transformarse en uno por autoridad. Recordemos que el periodo de 1847 a 1854 se distingue por un estado de relativa paz en el valle del Yaqui, cuyo origen se encuentra en una serie de pactos políticos, que se vieron reflejados en las leyes o legislaciones especiales para las sociedades indígenas que estuvieron fuertemente influidos por el levantamiento de $\mathrm{Mi}$ guel Esteban. Entre ellas, como mencionamos en el trabajo, se encontraba la "Ley para los pueblos indígenas de Sonora" que coincidió con el ascenso de Manuel María Gándara al poder del estado en 1853, la cual fue pieza fundamental para tener a los mayos bajo control, extendiendo el poder militar del capitán general del Yaqui a territorio Mayo.

Las legislaciones de 1853 son relevantes para representar la autoridad de Marquín. Si bien, éstas legitimaron su cargo político hasta su muerte, al mismo tiempo, la creación de cargos como los de subprefecto del Yaqui y jueces de paz, produjo que el poder de ac- 
ción en su demarcación menguara. Asimismo, este momento fue aprovechado por autoridades indígenas como alcaldes y gobernadores del Yaqui para posicionarse en contra de la concentración del poder de Marquín, cuestionando su autoridad y dirigiéndose a los pueblos yaquis para desacreditarlo. Lo anterior produjo que Mateo se sublevara al orden estatal y buscara en los afectados del Babójori y Aguacaliente a un grupo de seguidores que acordes con sus intereses, pretendían la defensa de sus territorios a través de la mano de un líder que podía negociar con Manuel María Gándara su objetivo.

Consideramos que otro de los aportes del presente trabajo es poner al descubierto los mecanismos mediante los cuales el gobierno estatal, a fin de evitar la concentración del poder en el capitán general, reconocieron como autoridades a alcaldes y gobernadores de los pueblos yaquis que regularmente se habían opuesto a la concentración del poder en manos de su capitán general. El caso concreto lo encontramos en la cuestión de los terrenos del Babójori y Aguacaliente, cercanos a la frontera de San José de Guaymas, cuya negociación se vio menguada con la salida de Manuel María Gándara de la gubernatura y la ocupación de la misma por Pedro Espejo en junio de 1855. En ese momento, comienzan las misivas de parte de Lorenzo Guapo de Huiviris y Pedro Balenzuela quienes informan negativamente acerca las actividades de Mateo Marquín en el río Yaqui. Posiblemente, estos jefes yaquis esperarán la destitución de Marquín una vez que su aliado principal ya no ocupaba la gubernatura. Dicha destitución no se concretó debido a lo efímero de los gobiernos que se sucedieron en Sonora en el periodo 1854-1856; Marquín murió en 1857 luchando a favor de Manuel María Gándara, en el conflicto que lo enfrentó a Ignacio Pesqueira, ostentando su cargo de capitán general para los yaquis, en tanto que para las autoridades estatales había pasado a ser un cabecilla rebelde.

Aún es bastante lo que falta por investigar con respecto a los líderes indígenas y el tipo de liderazgo que ejercieron en Sonora, por ejemplo, quedan por investigar los líderes ópatas y mayos por lo que esperamos que este artículo sirva de base para futuros trabajos que exploren la historia de los grupos indígenas desde el ángulo de sus líderes y el tipo de liderazgo que ejercieron. 


\section{Archivos}

Archivo General de la Nación, México (AGN) Archivo General del Estado de Sonora (AGES)

\section{BIBLIOGRAFÍA}

Acuña, Rodolfo. 1981. Caudillo sonorense. Ignacio Pesqueira y su tiempo. Colección problemas de México. México: Era.

Almada Bay, Ignacio. 2009. La conexión Yocupicio: soberanía estatal y tradición cívico-liberal en Sonora 1913-1939. México: El Colegio de México.

Bechis, Martha. 2008. "Los lideratos políticos en el área Araucopampeana en el siglo XIx: ¿autoridad o poder?” En Piezas de etnohistoria del sur sudamericano. Madrid: Consejo Superior de Investigaciones Científicas, 265-296.

Córdova Casas, César. 1994. "Costumbres normativas de los seris”. En Memorias del XVII Simposio de Historia y Antropología. Vol. 2. Hermosillo: Universidad de Sonora, 335-352.

De Jong, Ingrid. 2009. "Armado y desarmado de una confederación: El liderazgo de Calfucurá en el periodo de organización nacional (1852-1873)". Quinto Sol. Revista de Historia Regional (13): 11-45.

ELIzondo, Domingo. 1999. Noticia de la expedición militar contra los rebeldes seris y pimas del Cerro Prieto, Sonora, 1767-1771, ed., introd., notas y apéndices de José Luis Mirafuentes y Pilar Máynez. México: Universidad Nacional Autónoma de México, Instituto de Investigaciones Históricas.

Hernández Silva, Héctor Cuauhtémoc. 1996. Insurgencia y autonomía. Historia de los pueblos yaquis: 1821-1910. México: Ciesas, INI.

. 1997. "La lucha interna por el poder en las rebeliones yaquis del noroeste de México 1824-1899". En La reindianización de América siglo XIX, coord. Leticia Reina, 186-198. México: Siglo XXI.

Hrduikca, Alec. 1904. "Notes on the indian of Sonora, Mexico". American Anthropologist 1(6): (51-89). 
Hu Dehart, Evelyn. 1984. Yaqui Resistance and Survival: The Struggle for Land and Autonomy, 1821-1910. Madison: The University Winsconsin Press.

López CASTILlo, Gilberto. 2010. El poblamiento en tierra de indios cahitas transformaciones de la territorialidad en el contexto de las misiones jesuitas, 1591-1790. México: Siglo XXI, El Colegio de Sinaloa.

Medina Bustos, José Marcos. 2008. "La representación política de antiguo régimen y la transición al liberalismo en una zona de frontera, Sonora 1650-1824". Tesis de Doctorado en Ciencias Sociales, El Colegio de Michoacán.

. 2011. "Cargos militares indígenas en la transición del Antiguo Régimen al liberalismo. El caso de Sonora, México". Revista de Ciencias Sociales. Segunda época (20): 29-48.

Mirafuentes G., José Luis. 1994. "Colonial Expansion and Indian Resistance in Sonora: The Seri Uprisings in 1748 and 1750". En Violence, Resistance, and Survival in the Americas. Native Americans and the Legacy of Conquest, ed. William B. Taylor, 101-123. Washington: Smithsonian Institution.

Néspolo, Eugenia, María Laura Cutrera y Ariel Morrone. 2009. "El líder étnico, liderar y liderzgo. Los Yahatti, Lepin, Juan Manuel Cachul y Juan Catriel: hombres políticos en la frontera bonaerense". Revista Española de Antropología Americana 39(2): 83-100.

Ortega Noriega, Sergio, Ignacio Del Río, coords. 2010. Tres siglos de historia sonorense. 1530-1830. México: Universidad Nacional Autónoma de México.

Ortner, Sherry B. 1995. "Resistance and the Problem of Etnographic Refusal". Comparative Studies in Society and History 37(1): 173-193.

Padilla Ramos, Raquel, Zulema Trejo Contreras. 2012. "Guerra secular del yaqui y significaciones imaginario sociales". Historia Mexicana LXII(1): 59-103.

PÉREZ De Ribas, Andrés. 1645. Historia de los triunfos de nuestra santa fe entre gentes las más bárbaras, y fieras del nuevo Orbe: conseguidos por los Soldados de la Milicia de la Compañia de Jesús en las Misiones de la Provincia de Nueva España. Madrid: Alfonso de Paredes, junto a los estudios de la Compañía. 
Quijada Hernández, Armando y Juan Antonio Ruibal Corella. 1997. Historia general de Sonora, tomo III. 2a. ed. Hermosillo: Ed. Instituto Sonorense de Cultura.

Radding, Cynthia. 1997. Wandering Peoples Colonialism, Ethnic Spaces, and Ecological Frontiers in Northwerstern Mexico, 17001850. Durhan: Duke University.

. 1995. Entre el desierto y la sierra, las naciones o'odham y tegüima de Sonora. 1530-1840. México: Ciesas.

Ramírez Zavala, Ana Luz. 2014. “De todo se han aprovechado esos hombres políticos y revolucionarios'. Los Yaquis durante el proceso de formación del Estado posrevolucionario: negociación y cambio cultural, 1920-1940". Tesis de Doctorado en Historia, El Colegio de México.

Ruibal Corella, Juan Antonio y Armando Quijada. 1997. Historia general de Sonora: periodo México independiente 1831-1883. Hermosillo: Gobierno del Estado de Sonora.

SpICER, Edward. 1994. Los yaquis historia de una cultura. México: Universidad Nacional Autónoma de México.

Swartz, Marc J., Victor W. Turner y Arthur Tuden. 1966. Political Anthropology. Chicago: Aldine Publishing Company, 1-41.

Trejo, Zulema. 2004. "Redes, facciones y liberalismo. Sonora 1850-1876". Tesis de Doctorado, El Colegio de Michoacán.

. 2012. Redes, facciones y liberalismo en Sonora 1856-1870. México: Colegio de Sonora, Colegio de Michoacán.

. 2013. "Leyes especiales para el gobierno de los pueblos indígenas de Sonora. 1831-1853". Fronteras de la Historia 18(2): 105-131.

Trejo Contreras, Zulema e Ivan Revilla. 2011. "El capitán general del Yaqui, ¿'figura heroica o cabecilla rebelde?” En XXII Simposio de la Sociedad Sonorense de Historia, noviembre de 2009. Hermosillo: El Colegio de Sonora.

Yáñez Moreno, Pedro. 2012. “'Sé que estoy enfermo, ¿y qué hacer?' La diabetes mellitus y sus significados entre los comcaac de Socaaix (Punta Chueca), Sonora”. Tesis de Maestría en Ciencias Sociales, El Colegio de Sonora. 